\title{
The Seminoma Cell Line TCam-2 is Sensitive to HDAC Inhibitor Depsipeptide but Tolerates Various Other Chemotherapeutic Drugs and Loss of NANOG Expression
}

\author{
Daniel Nettersheim, ${ }^{1}$ Ad Gillis, ${ }^{2}$ Katharina Biermann, ${ }^{2}$ Leendert H.J. Looijenga, ${ }^{2}$ and Hubert Schorle ${ }^{1 *}$ \\ 'Department of Developmental Pathology, Institute of Pathology, University of Bonn, Bonn, Germany \\ ${ }^{2}$ Department of Pathology, Erasmus MC-University Medical Center Rotterdam, Josephine Nefkens Institute; Daniel den Hoed \\ Cancer Center, Rotterdam, The Netherlands
}

\begin{abstract}
Seminomas and embryonal carcinomas (EC) are both type II germ cell tumor (GCT) entities and develop from the same precursor lesion (carcinoma-in situ, CIS). However, they show significant differences in growth behavior, differentiation potential, and gene expression. Although ECs are prone to differentiate into all three germ layers and give rise to the nonseminomatous GCT entities teratoma, choriocarcinoma, and yolk-sac tumor, differentiation of seminomas to these entities is only rarely observed. This might reflect the ability of seminomas to actively inhibit differentiation processes evoked by environmental cues. Also, it is not known why CIS gives rise to seminoma in some patients and to non-seminoma in the others. Here, we treated the seminoma-like cell line TCam-2 with the HDAC-inhibitor Depsipeptide, the global demethylating agent 5-aza-2'-deocycytidine, all-trans retinoic acid and the monaminooxidase inhibitor Tranylcipromine and also used knock down approaches to reduce expression of the pluripotency marker NANOG and/or the inhibitor of primordial germ cell differentiation TFAP2C. We found that TCam-2 cells induce apoptosis when treated with Depsipeptide ( $>10 \mathrm{nM})$ but are resistant to treatments with 5-aza-2'-deocycytidine, all-trans retinoic acid and Tranylcipromine, highlighting Depsi as a treatment option for seminomas. We show that TCam-2 cells up-regulate endoderm- and throphectoderm-associated genes after down-regulation of NANOG expression; however, morphologically no indications of differentiation could be found. Instead, we observed up-regulation of OCT3/4 and SOXI7 in TCam-2-NANOG knockdown and speculate that this compensates for the loss of the NANOG protein. Hence, NANOG is not a primary target gene responsible for the inhibition of differentiation in seminomas. (c) 201I Wiley Periodicals, Inc.
\end{abstract}

\section{INTRODUCTION}

Seminomas and embryonal carcinomas (ECs) belong to the class of type II germ cell tumors (GCTs) (Oosterhuis and Looijenga, 2005). In contrast to seminomas, ECs are prone to differentiate into all three germ layers and develop into teratomas, choriocarcinomas, and yolk-sac tumors. The differentiation abilities of seminomas are only poorly understood. It is postulated that seminomas are not able to differentiate in vivo (Battifora et al., 1984; Srigley et al., 1988), although some rare cases of seminomatous in vivo differentiation were described (Czaja and Ulbright, 1992) and a transition step to ECs is hypothesized (Oosterhuis and Looijenga, 2005 \#23). The TCam-2 cell line resembles a seminoma since it expresses markers of primordial germ cells (PGC) and seminomas as well as markers indicative for pluripotency and self-renewal (KIT, TFAP2C, BLIMP1, VASA, GDF3, MCFD2, D2-40, SOX17, NANOG, OCT3/4) (de Jong et al., 2008a; Eckert et al., 2008). Alike seminomas, TCam-2 cells lack expression of $S O X 2$ but are positive for SOX17 (de Jong et al., 2008b). Furthermore, TCam-2 cells clearly cluster with seminoma tissues in a cDNA microarray experiment (Eckert et al., 2008). Therefore, TCam-2 is a valuable model to analyze seminoma development and progression in vitro.

In this study, we used different chemical compounds and screened for their potential to initiate differentiation of TCam-2 cells and for their suitability as a treatment option for seminomas. We treated the cells with the histone-deacetylase

\footnotetext{
Additional Supporting Information may be found in the online version of this article.

Supported by: DFG Grant, Grant number: Scho 503-9.

*Correspondence to: Hubert Schorle, Department of Developmental Pathology, Institute of Pathology, Sigmund-Freud-Strasse 25, Bonn 53127, Germany. E-mail: hubert.schorle@ukb.uni-bonn.de

Received 9 June 2011; Accepted 14 July 2011

DOI 10.1002/gcc.20918

Published online 24 August 2011 in

Wiley Online Library (wileyonlinelibrary.com)
} 
inhibitor (HDI) Depsipeptide (Depsi), the global demethylating agent 5-aza-2'-Deoxycytidine (5aza), the inducer of differentiation all-trans retinoic acid (ATRA) and the monoaminooxidaseinhibitor (MAOI) Tranylcypromine (Tranyl). The HDI Depsi inhibits deacetylation of histones and thereby maintains an euchromatinic state, which is associated with hypertranscription (Thiagalingam et al., 2003; Monneret, 2005 \{\#273\}; Chai et al., 2008). Furthermore, Depsi is a treatment option for many human cancer types because of its selective cytotoxicity against cancer cells (Ueda et al., 1994; Byrd et al., 1999). The nucleoside analogon 5aza is incorporated into the newly synthesized DNA strand during replication and prevents its remethylation, leading to global demethylation and re-expression of epigenetically silenced genes (Chai et al., 2008; Fabiani et al., 2010). Additionally, 5aza was shown to decrease strongly proliferation of breast cancer cells (Zhang et al., 2007). ATRA induces differentiation of the EG cell line NCGIT into all three germ layers and of F9 cells into endoderm lineage (Strickland and Mahdavi, 1978; Damjanov et al., 1993). Furthermore, NT2 cells differentiate into neurons after ATRA treatment and downregulate the pluripotency and self-renewal associated genes NANOG and OCT3/4 (Deb-Rinker et al., 2005). The MAO LSD1 is a lysine specific demethylase, which is claimed as a novel therapeutic target for estrogen receptor-negative breast cancers (Lim et al., 2010). The activity of LSD1 can be blocked by the MAOI Tranyl, leading to de-repression of LSD1 target genes. Taken together these chemical compounds are associated with induction of differentiation, apoptosis, cell cycle arrest, global demethylation, histone modifications, and hypertranscription. The effects of these compounds on seminoma cells are largely unknown; therefore, our study should help to identify further genes and pathways that are active in the process of non-seminomatous differentiation and screen for the compounds' potential to be a seminoma treatment option.

The homeobox transcription factor NANOG plays a crucial role in maintaining self-renewal in concert with OCT3/4 and SOX2 in pluripotent cells like embryonic stem cells (ESCs) (Mitsui et al., 2003; Hyslop et al., 2005; Pan and Thomson, 2007). A $N A N O G$ knock down in ESCs or NCCIT cells leads to differentiation into extraembryonic endoderm and all three germ layers, respectively (Chambers et al., 2003; Hyslop et al., 2005; You et al., 2009). Tfap2c/TFAP2C has been shown to block mesodermal differentiation during early murine germ cell development and in in vitro generated PGCs as well as TCam-2 cells (Weber et al., 2010). Therefore, we reasoned that knock down of both transcription factors alone or combination with each other might induce somatic differentiation of TCam-2 cells.

You et al., (2009) could show that treatment with the HDACi Apicidin, ATRA or the use of siRNA based approaches led to significant downregulation of $N A N O G$ in the EC cell line NCCIT, resulting in down-regulation of OCT3/4 and SOX2, cell cycle inhibition and differentiation into all three germ layers. The authors discuss that targeting $N A N O G$ might be an approach for therapy of poorly differentiated GCTs. Referring to this publication, our data should help to highlight important differences or similarities between seminomas and ECs concerning drug response and the role of NANOG protein in maintaining an undifferentiated state.

Here, we demonstrate that TCam-2 cells are resistant to the differentiation inducing effects of Depsi, 5aza, ATRA, and Tranyl, as judged by cellular morphology and expression of key marker genes. We show that Tranyl dramatically reduces the methylation status of the histones $\mathrm{H} 3 \mathrm{~K} 4$ and $\mathrm{H} 3 \mathrm{~K} 9$ and Depsi concentrations $\geq 10 \mathrm{~nm}$ induce apoptosis. Further, knock down of NANOG resulted in up-regulation of the extraembryonic endoderm- and trophectoderm-associated genes GATA2, GATA4, GATA6, and DNA-methylating enzymes DNMT3a and DNMT3l without induction of differentiation. Instead, we observed an up-regulation of OCT3/4 and SOX17, probably compensating for the lack of the NANOG protein. Reduction of TFAP2C expression resulted in de-repression of MYOD1 and HAND1 as described previously (Weber et al., 2010) as well as down-regulation of DNMT3l.

\section{MATERIALS AND METHODS}

\section{Cell Culture}

TCam-2 cells (obtained from Dr. Janet Shipley, Institute of Cancer Research, Sutton, England) were grown in RPMI (10\% FCS (FCS), $1 \%$ Penicillin/Streptomycin, $200 \mathrm{~mm}$ L-Glutamine), whereas the EC cell lines 2102EP and NCCIT (obtained from Dr. Stefanie Gläsener, UKE Hamburg, Germany) were grown in DMEM medium (10\% FCS, 1\% Penicillin/Streptomycin, 200 mu L-Glutamine) at $37^{\circ} \mathrm{C}$ and $5 \% \mathrm{CO}_{2}$. 


\section{DNA Isolation}

DNA was isolated from TCam-2 cells, normal testis tissue and seminoma tissue by adding 350 $\mu l$ lysis-buffer (50 mm TRIs-HCl, pH 8; $100 \mathrm{~mm}$ EDTA; $100 \mathrm{~mm} \mathrm{NaCl} ; 1 \% \mathrm{SDS})$ and $40 \mu \mathrm{l}$ Proteinase $\mathrm{K}(10 \mathrm{mg} / \mathrm{ml})$ to the cell pellet. The cells were digested over night at $55^{\circ} \mathrm{C}$. The next day $150 \mu \mathrm{NaCl}$ (5 M) was added and cells were shaken for $5 \mathrm{~min}$, followed by a centrifugation step $(13,000 \mathrm{rpm})$ for $10 \mathrm{~min}$. Supernatant was transferred to $500 \mu \mathrm{l}$ isopropanol and centrifuged for $10 \mathrm{~min}$ at $13,000 \mathrm{rpm}$ at $4^{\circ} \mathrm{C}$. Precipitated DNA was washed twice with $500 \mu \mathrm{l} 80 \%$ ethanol and air-dried. DNA was resolved in $200 \mu \mathrm{l}$ water for $1 \mathrm{hr}$ at $55^{\circ} \mathrm{C}$. Concentration and 260/280 nm and $260 / 230 \mathrm{~nm}$ purity ratios were determined by NanoDrop (Peqlab, Erlangen, Germany).

\section{RNA Preparation}

Total RNA was extracted with TRIzol according to the manufacturer's manual (Invitrogen, Karlsruhe, Germany). RNA quality was assessed by photometric measurement at ratios 260/280 $\mathrm{nm}$ and 260/230 $\mathrm{nm}$.

\section{Protein Isolation}

Proteins were isolated by RIPA buffer [50 $\mathrm{mm}$ TRIS-HCl pH 8, 150 mm NaCl, 1\% NP-40, 0.5\% Sodium Deoxycholate, $0.1 \%$ SDS +1 tablet of protease inhibitor cocktail (Roche, Mannheim, Germany)]. Lysates were incubated for $30 \mathrm{~min}$ at $4^{\circ} \mathrm{C}$, followed by a $20 \mathrm{~min}$ centrifugation step at $12,000 g, 4^{\circ} \mathrm{C}$. The supernatant was used for Western blot analysis. The protein concentration was determined by the BCA Protein Assay Kit (Pierce, Rockford).

\section{Western Blot Analysis}

For protein analysis, Mini-PROTEAN Electrophoresis Cell and Mini Trans-Blot system was used (Bio-Rad, Munich, Germany). Protein was prepared using standard protocol and electrophoresed at $30 \mathrm{~mA}$ for $90 \mathrm{~min}$. The gel was blotted onto a PVDF membrane in a Bio-Rad blotting chamber over night at $30 \mathrm{~V}$ at $4^{\circ} \mathrm{C}$ according to published protocols (Eckert, et al., 2008). After blocking in PBSTM (PBS, 0.1\% v/v Tween 20, $5 \%$ low fat milk powder) primary antibodies were incubated in PBSTM for $3 \mathrm{hr}$ at room temperature (RT). The secondary antibodies were diluted in PBSTM as recommended by the distributor and were incubated with membranes for
$1 \mathrm{hr}$ at R'T. Finally, the membrane was incubated in $2 \mathrm{ml}$ PierceSuper Signal West Pico chemiluminescent substrate (Perbio, Bonn, Germany, Prod. No. 34080) and the signal was detected using Kodak X-Ray film (Kodak, Germany). See Supporting Information Table 1 for antibody details and dilution ratios.

\section{RT-PCR}

For RT-PGR $500 \mathrm{ng}$ of DNAseI (NEB, Frankfurt, Germany) digested RNA template was used. First-strand cDNA synthesis and PCR reaction were performed according to the Super Script III manual (Invitrogen). PCR was performed using $95^{\circ} \mathrm{C} / 2 \mathrm{~min}, 30$ cycles of $94^{\circ} \mathrm{C} / 30 \mathrm{~s}, 57-60^{\circ} \mathrm{C} / 30 \mathrm{~s}$ and $72^{\circ} \mathrm{C} / 45 \mathrm{~s}$. See Supporting Information Table 2 for primer sequences.

\section{Quantitative RT-PCR (qRT-PCR)}

High-quality total RNA was extracted from TCam-2 samples using an RNAqueous-4PCR kit (Ambion/Applied Biosystems, Nieuwerkerk, Netherlands) according to the manufacturer's instructions. Samples were treated with DNase and checked for residual DNA contamination by PCR. The cDNA was diluted 1:10, 1:20, 1:40, and $1: 80$, afterward HPRT was amplified by quantitative RT-PCR (qRT-PCR). From these values, the dilution (corresponding to a $\mathrm{Ct}$ of 23) for the final qRT-PCR amplification experiment of the target genes was chosen. qRT-PCR experiments were performed in technical triplicates. qRTPCR was performed using the 7900HT Fast RealTime PCR System (Applied Biosystems). Quantitative values were obtained from the Ct. Marker gene mRNA was quantified relative to HPRT $\left[\right.$ mRNA value $\left.=2^{\text {(mean Ct HPRT }- \text { Ct mRNA marker })}\right]$, in addition $\Delta \Delta$-Ct values were calculated for si/ sh-transfected samples versus scrambled-siRNA/ pRNATinH1.2-Neo-vector-transfected TCam-2 cells.

\section{Sodium Bisulfite DNA Methylation Analysis}

To determine the methylation level of the different cell types, $500 \mathrm{ng}$ DNA of each sample was treated with sodium bisulfite to convert all unmethylated cytosine-residues to uracil. The procedure was performed after the published protocol of the EpiTect Bisulfite Kit (Qiagen, Hilden, Germany). The converted region was amplified by PCR (see below). The PCR product was ligated into pCR2.1-Vector at a molar ratio of 
3:1 (insert:vector) using the TA cloning Kit (Invitrogen, Karlsruhe, Germany) and competent E. coli TOP10 bacteria were transformed. Finally, after verifying integration of the correct inserts by a restriction digest the isolated plasmids were sequenced (Entelechon GmbH, Regensburg, Germany).

\section{Sodium Bisulfite PCR}

A $150 \mathrm{ng}$ sodium bisulfite treated DNA was used for each PCR reaction. PCR was carried out at $95^{\circ} \mathrm{C}$ for $2 \mathrm{~min}$, followed by 40 cycles of $94^{\circ} \mathrm{C}$ for $45 \mathrm{~s}, 54^{\circ} \mathrm{C}$ for $45 \mathrm{~s}$ and $72^{\circ} \mathrm{C}$ for $45 \mathrm{~s}$. The following primers, designed to recognize sodium bisulfite converted DNA were used: LINE1BISF: 5'-TTTTTTGAGTTAGGTGTGGG-3'，LINE1BISR: 5'-TCTCACTAAAAAATACCAAACAA-3'. RAR-ß2BISF: 5'-AAGTAGTA GGAAGTGAGTT GTTTAGA-3', RAR-ß2BISR: 5'-CCAAATTCTC CTTCCAAATAA-3'.

\section{Depsi, 5aza, ATRA, and Tranyl Treatment of Cell Cultures}

Depsi, 5aza, and Tranyl were dissolved in DMSO, ATRA was dissolved in ethanol (EtOH). $1 \times 10^{4}$ TCam-2 cells were treated with 500 pM$100 \mathrm{~nm}$ Depsi, $1 \mu \mathrm{m}-1 \mathrm{~mm}$ 5aza, $1 \mu \mathrm{m}-10 \mathrm{~mm}$ ATRA and $200 \mu \mathrm{M}$ Tranyl for 8 days. $1 \times 10^{4}$ 2102EP cells were treated with $10 \mu \mathrm{M} 5 \mathrm{aza}$ and 1 $\times 10^{4}$ NCGIT cells were treated with $20 \mu \mathrm{M}$ ATRA for 8 days. Corresponding amounts of the solvents (DMSO, Ethanol) served as controls. In combinatory approaches, cells were first treated with $5 \mathrm{~nm}$ Depsi for 4 days and then $10 \mu \mathrm{m} 5 \mathrm{aza}$ or $10 \mu \mathrm{m} 5 \mathrm{aza}+20 \mu \mathrm{m}$ ATRA was added.

\section{Transfection of TCam-2 and 2102 EP Cells}

Each siRNA was transfected at a ratio of 5:1 ( $\mu$ l FuGeneHD : $\mu \mathrm{g}$ siRNA) in a total volume of $100 \mu \mathrm{l}$, while shRNA-vectors were transfected at a ratio of 5:2 ( $\mu \mathrm{l} \mathrm{FuGeneHD} \mathrm{:} \mu \mathrm{g}$ shRNA-vector) in a total volume of $100 \mu$ l. Complex formation was performed in RPMI medium without any supplements for $20 \mathrm{~min}$ at room temperature. For each experiment, $2 \times 10^{5}$ cells were seeded onto 6-well plates one day before transfection. Scrambled siRNA (all stars negative control siRNA, Qiagen, Hilden, Germany) and fluorescent-tagged siRNA (BLOCK-iT Fluorescent Oligo, Invitrogen, Karlsbad, Germany) were used as transfection controls and to monitor the transfection process. NANOG and TFAP2C siRNA were obtained from Santa Cruz (sc-4398, sc-29696,
Santa Cruz, Santa Cruz, USA). NANOG shRNA oligonucleotides were synthesized by Sigma Aldrich (Sigma Aldrich, Taufkirchen, Germany). NANOG shRNA sense: 5'-CGTGGAACAGTCC CTTCTATA-3'. shRNA oligos were cloned into the pRNATinH1.2-Neo expression plasmid (GenScript, Piscataway).

\section{Annexin V Staining}

The "BD Pharmigen PE Annexin V Apoptosis Detection Kit I" (BD, Heidelberg, Germany) was used to determine apoptosis rates. $1 \times 10^{5}$ TCam-2 cells were plated in a 6 -well plate. The cells were treated for 4,8 , and $16 \mathrm{hr}$ with different concentrations of Depsi; then, the apoptosis rates were measured. Therefore, TCam-2 cells were trypsinized and resuspended in $100 \mu \mathrm{l}$ "BD Annexin V binding buffer". Five microliter of "PE Annexin V" and $5 \mu \mathrm{l}$ of "7-AAD" was added to each sample. Additionally, TCam-2 cells were stained with Annexin $\mathrm{V}$ and 7-AAD alone as controls. Annexin V+/7-AAD-, AnnexinV-/7-AAD+, Annexin V+/7-AAD+, Annexin V-/7-AAD-, and control cells were analyzed by FACS sorting after $15 \mathrm{~min}$ of incubation and addition of $400 \mu \mathrm{l}$ binding buffer. In total, $1 \times 10^{5}$ cells were counted per sample.

\section{RESULTS}

Seminomas represent the undifferentiated and most primitive entity of germ cell tumors. They express markers of pluripotency and markers for early PGCs. Here we tested the ability of seminoma cells to respond to various chemical and genetic interventions using TCam-2 as a model. We chose several chemical compounds based on their ability to induce differentiation, apoptosis, and cell cycle arrest.

First, TCam-2 cells were treated with a broad range of concentrations (Depsi $1 \mathrm{~nm}-100 \mathrm{~nm}$; 5aza $1 \mu \mathrm{M}-1 \mathrm{~mm}$; ATRA $1 \mu \mathrm{M}-10 \mathrm{~mm}$ ) of drugs for 8 days and screened for morphological changes before choosing the final concentrations used in this study. Pictures of TCam-2 cells after an 8 day treatment with the highest concentrations are shown in Supporting Information Figure 1 (Supporting Information Fig. S1A-1E). An incubation time of 8 days was chosen, because TCam-2 cells divide very slowly ( $58 \mathrm{hr}$ doubling time) (Eckert et al., 2008). We reasoned that induction of differentiation and/or epigenetic changes that depend on DNA-replication, e.g., demethylation 

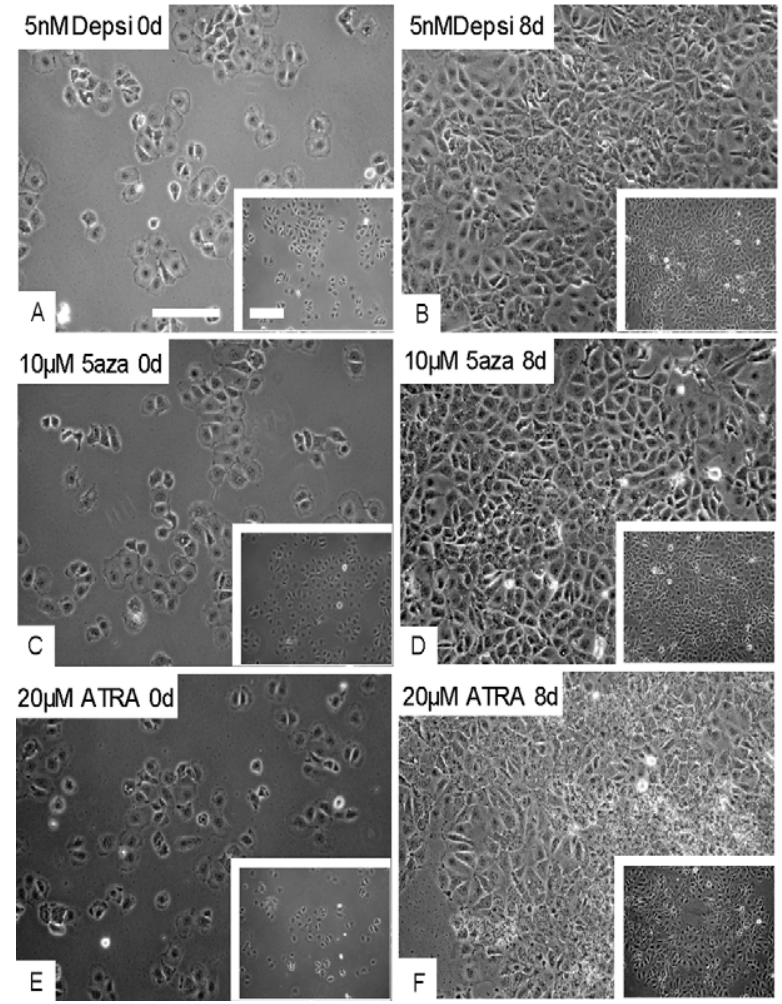

Figure I. Brightfield pictures of TCam- 2 cells after $\mathrm{I}$ and 8 days of treatment with $5 \mathrm{nM}$ Depsi (A, B), $10 \mu \mathrm{M} 5 \mathrm{aza}$ (C, D), $20 \mu \mathrm{M}$ ATRA (E, F), 5 nм Depsi + $10 \mu \mathrm{M}$ 5aza (G, H), 5 nм Depsi + $10 \mu \mathrm{M}$ $5 a z a+20 \mu \mathrm{M}$ ATRA (I, J) and $200 \mu \mathrm{M}$ Tranyl (K, L). Brightfield pic-

through 5aza, might be observed best after at least three replication cycles, i.e., 8 day period. Besides a massive cell death after application of $\geq 10$ nm Depsi (Supporting Information Fig. 1A1D) no morphological changes were found during treatment with 5aza or ATRA. Therefore, we choose to use a final Depsi concentration of $5 \mathrm{~nm}$. Although 5aza treatment did not result in alteration of TCam-2 morphology (Supporting Information Fig. 1E-1H) we observed demethylation of LINE-1 promoter elements (Supporting Information Fig. S2A-2F) at the concentrations used $(1 \mu \mathrm{M}$ and $10 \mu \mathrm{M}$ ) indicating that the amount of 5aza is sufficient to interfere with DNA-methylation (Chai et al., 2008). Because even high levels of ATRA did not induce differentiation in TCam2 cells (Supporting Information Fig. 1E-1F), we decided to use a concentration that was able to induce differentiation of NCCIT EC-cells in our setting $(20 \mu \mathrm{M})$ (Supporting Information Fig. S2G).

After 8 days in culture, the morphology of the NCCIT cells started to change and appear flat, large and epidermal-like (Supporting Information Fig. S1G) as described before (Damjanov et al.,

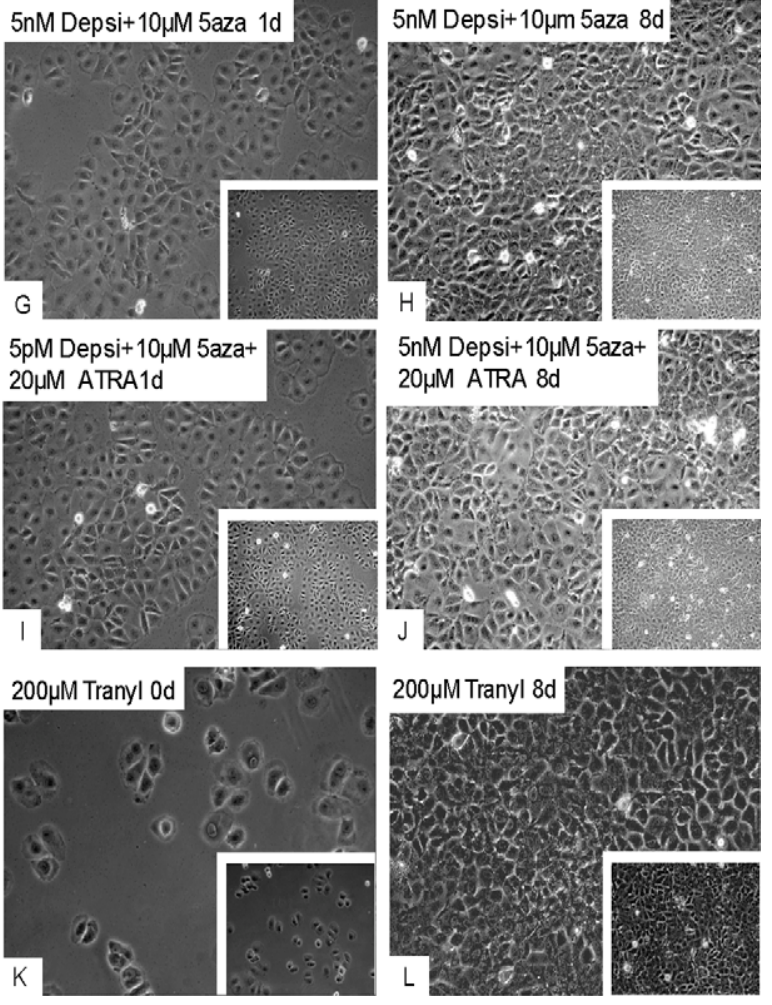

tures of TCam-2 cells cultivated in presence of corresponding amounts of the solvents are shown in the lower, right corners. DMSO was used as control for Depsi, 5aza, and Tranyl, while Ethanol was used as control for ATRA. Scale-bars: $100 \mu \mathrm{m}$

1993). ATRA signals via the retinoic acid receptor- $\beta 2$ (RAR-B2). Expression of the receptor in TCam-2 cells was demonstrated by RT-PCR analysis (Supporting Information Fig. S2I). Furthermore in TCam-2 cells, the promotor of the $R A R-B 2$ gene is hypomethylated as shown by sodium bisulfite sequencing (Supporting Information Fig. S2H). Therefore, retinoic-acid signaling via the RAR-B2-receptor, whose expression is often reduced or absent in cancer cells due to hypermethylation is enabled in TCam-2 cells (Mongan and Gudas, 2007). Next, Western blot analyses demonstrated the expression of the lysine specific demethylase (LSD1) (Lim et al., 2010), which is a target of the MAOI Tranyl (Supporting Information Fig. S2J).

HDI's like Depsi are able to maintain an euchromatinic status by inhibiting histone deacetylases, while 5aza supplementation has been shown to result in global demethylation of the genome (Ghoshal et al., 2005). Thus, both chemicals are able to promote the de-repression of epigenetically silenced genes. Therefore, we applied the chemicals alone (Depsi $5 \mathrm{~nm}$, 5aza $10 \mu \mathrm{M}$ ) 
and in combination to treat TCam-2 cells for 8 days. In addition, TCam-2 cells were treated with ATRA (20 $\mu \mathrm{M}, 8$ days) which was shown to induce differentiation in a broad range of cell types, like ESCs and EC cells (Damjanov et al., 1993; Wobus et al., 1997; Guan et al., 2001). However, all these experimental setups did not induce a change in morphology, which would indicate differentiation of TCam-2 cells (Fig. 1A1H, Supporting Information Fig. S1). Of note, during treatment with $10 \mathrm{~mm} 5 \mathrm{aza}$ for 8 days, expression of SOX2 and SOX17 remained unchanged (Supporting Information Fig. S3A). In untreated TCam-2 cells the promoter of the SOX2 gene was found completely hypomethylated (Supporting Information Fig. S3B). Hence, the promoter of $\mathrm{SOX} 2$ seems not to be silenced by DNA methylation in TCam-2 cells.

Most interestingly, Depsi concentrations $\geq 10$ nM were lethal to the TCam-2 cells already after $16 \mathrm{hr}$ of treatment as demonstrated by Annexin V staining and by morphology (Supporting Information Figs. S1A, 1B, and S4). Since single treatment with ATRA, 5aza or Depsi alone did not result in induction of differentiation of TCam-2 cells, we reasoned that global demethylation by 5 aza and induction of an euchromatinic state by Depsi might force TCam-2 cells to differentiate in response to ATRA. Therefore, TCam-2 cells were treated with for 8 days a combination of 5aza $(10 \mu \mathrm{M})$, Depsi (5 nM) and ATRA (20 $\mu \mathrm{M})$. Again, no morphological differences could be found (Figs. 1I and 1J). Furthermore, cells were treated with Tranyl $(200 \mu \mathrm{M})$ and screened for morphological changes during an 8-day cultivation period (Fig. 1K and 1L). Again, we were not able to detect any morphological changes or alterations in growth behavior.

Next, we screened for alterations of gene expression during treatment with these compounds alone and in combination with each other. We analyzed expression of markers for PGCs/germ cell tumors (BLIMP1, KIT, TFAP2C, VASA, BOULE), self-renewal/pluripotency (NANOG, $O C T 3 / 4, S O X 2)$, and somatic differentiation (PAX6) (Figs. 2A-2D). Eight days of treatment resulted in up-regulation of $P A X 6$ in case of treatment with 5 aza (Fig. 2A). Induction of PAX6 after 5aza mediated demethylation has been described in several tumors and tumor cell lines (Salem et al., 2000). Treatment with Tranyl resulted in complete demethylation of the lysines 4, 9, and 36 on histone $\mathrm{H} 3$ from day 8 on (Fig. 2G). However, to our surprise expression of most marker genes remained unaffected and only a moderate up-regulation of the meiotic germ cell marker BOULE was detected (Fig. 2D).

Next, we addressed the question whether down-regulation of the pluripotency marker NANOG and/or the germ cell marker TFAP2C would induce differentiation of TCam-2 cells. Using a siRNA approach, the levels of NANOG could be reduced below the detection limit of the Western blot; the levels of TCFAP2C were reduced by $\sim 80 \%$ (Fig. 3A). Using RT-PCR, knock down of $N A N O G$ and/or TFAP2C could be verified on RNA level (Figs. $3 \mathrm{~B}$ and $3 \mathrm{C}$ ). Knock down of $N A N O G$ and $N A N O G / T F A P 2 C$ led to an up-regulation of $O C T 3 / 4$ and $S O X 17$ levels and moderate reduction in $G D F 3$ expression was detected (Fig. 3C). The up-regulation of OCT3/4 was verified by Western blotting and we did not detect up-regulation of the SOX2 protein (Supporting Information Fig. S5). Additionally, the levels of DNMT3a, DNMT3l, GATA2, GATA4, GATA6, and BRACHYURY increased after NANOG knockdown indicating onset of differentiation. Interestingly, knock down of both $N A N O G$ plus TFAP2C or TFAP2C alone resulted in a strong reduction of DNMT3/ levels, while DNMT3a expression remained unaffected. In contrast, NANOG knock down led to induction of DNMT3l and DNMT3a expression, suggesting that NANOG and TCFAP2C have opposing functions in DNMT regulation. As reported previously, reduction of TFAP2C led to up-regulation of mesodermal markers MYOD1 and HAND1 (Fig. 3B) (Weber et al., 2010). The cells did not show a change in morphology $48 \mathrm{hr}$ after siRNA transfection (data not shown).

Since the siRNA mediated reduction of $N A N O G$ indicated that the TCam-2 cells initiated differentiation we needed to address the effect of a permanent reduction of NANOG in this cell line. Hence, four clones were established expressing shRNA-constructs, which displayed 90-100\% reduction of NANOG on the protein level (Fig. 4A, TCam-2- $\Delta$ NANOGsh1-4). Using RT-PCR and qRT-PCR on TCam-2- $\triangle$ NANOGsh2 we could verify the up-regulation of OCT3/4 and SOX17 seen in the siRNA experiments (Fig. 4C). However, to our surprise there was no effect on the other genes that were deregulated after transient reduction of $N A N O G$. Again, we were not able to detect any morphological differences between TCam-2- $\triangle$ NANOGsh-clones and parental TCam-2 cells (data not shown).

Finally, we asked if lack of $N A N O G$ would sensitize TCam-2 cells to the treatment with epigenetic modifiers 5aza or Depsi. Therefore, 
A

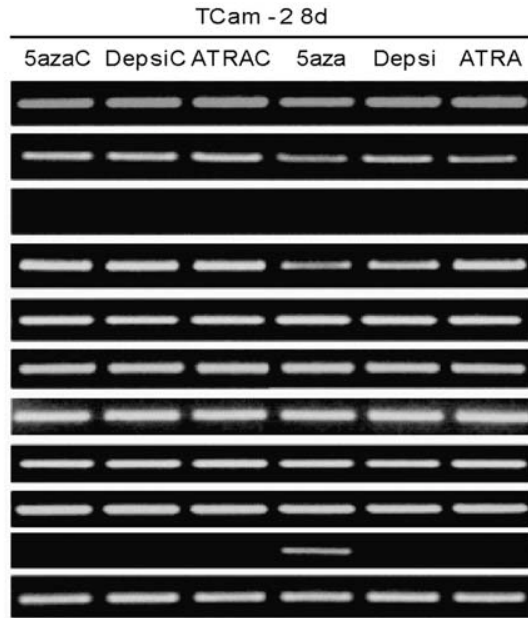

C
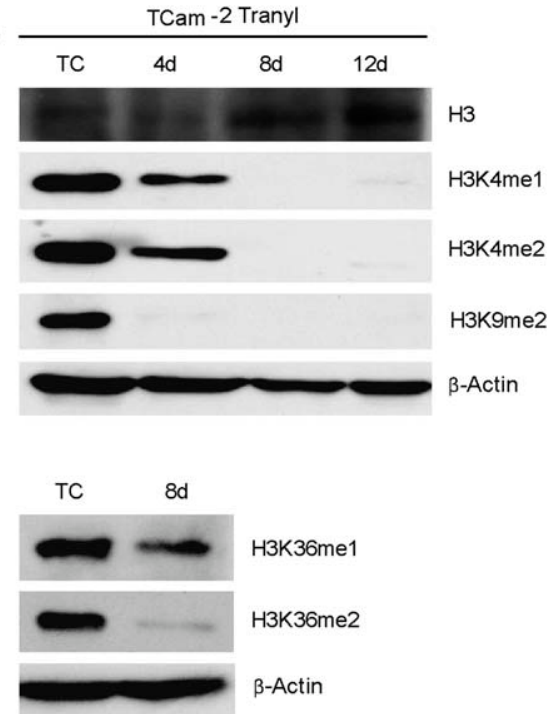

Figure 2. A: RT-PCR of RNA from TCam-2 cells of markers indicated after treatment with 5aza, Depsi, and ATRA and with the solvents only (5azaC, DepsiC, ATRAC). B: RT-PCR of indicated markers after combined treatment of TCam-2 cells with 5aza+Depsi (5/D), $5 a z a+D e p s i+A T R A(5 / D / A)$ and the solvents only (5/DC, 5/D/AC) C: Western blot analysis of the methylation status of lysines 4, 9, and 36 on histone 3 (H3K4mel, H3K4me2, H3K9me2, H3K36mel,

TCam-2- $\Delta$ NANOGsh2 was treated with 5aza, Depsi and 5aza plus Depsi. Again, no morphological changes could be observed after 8 days (data not shown). These results demonstrate that seminoma-like TCam-2 cells, in contrast to EC cells, can cope with many chemical and genetic stressors without induction of differentiation.

\section{DISCUSSION}

In this study, we analyzed the response of the seminoma-like cell line TCam-2 to different therapeutic drugs and report the effects after knock
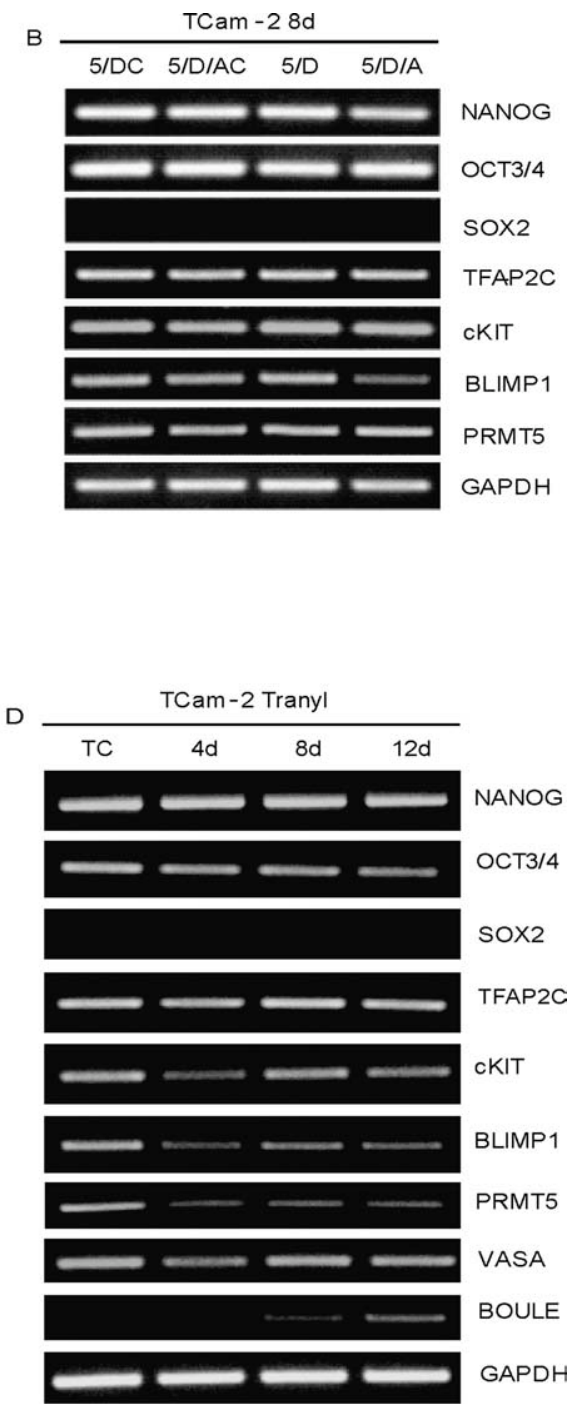

H3K36me2) in TCam-2 cells after 4,8 , and 12 days of Tranyl treatment. Unmethylated histone $3(\mathrm{H} 3)$ and $\boldsymbol{\beta}$-ACTIN ( $\beta$-Actin) served as controls. D: RT-PCR of indicated markers in TCam-2 cells after 4, 8 , and 12 days of Tranyl. TCam- 2 cells cultivated in the presence of the solvent for 12 days served as control (TC). GAPDH served as housekeeper control in all RT-PCR experiments.

down of $N A N O G$ and TFAP2C in this cell line. We demonstrate that the cells tolerate application of a broad range of agents and show no tendency to differentiate. Furthermore, TCam-2 cells can tolerate the loss of the pluripotency marker $N A N O G$ and down-regulation of TFAP2C. However, as a consequence, we observe an up-regulation of OCT3/4 and SOX17 and speculate that this mechanism compensates for the loss of NANOG. Our data might help to understand important differences between seminomas and ECs in vivo regarding drug treatment and differentiation abilities. 
A

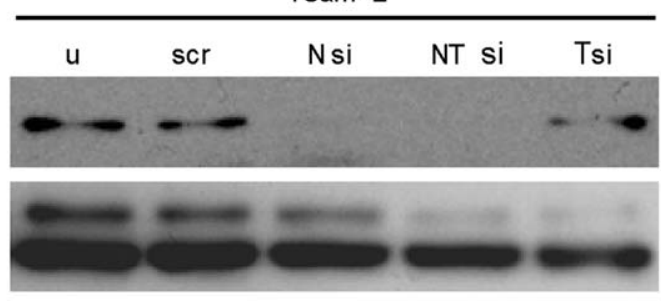

B

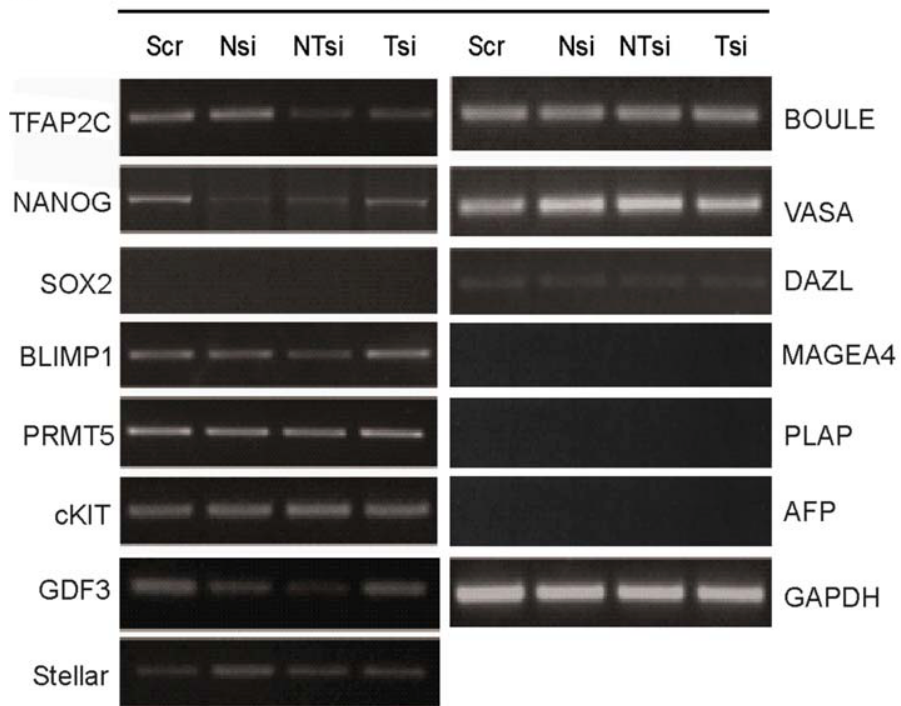

NANOG

TFAP2C

$\beta$-Actin
Figure 3. A: Western blot analysis of NANOG and TFAP2C expression in TCam-2 cells $48 \mathrm{hr}$ after transfection of NANOG (Nsi), NANOG+TFAP2C (NTsi), TFAP2C (Tsi) siRNA, and scrambled RNA (scr). (u) untransfected TCam-2. B-ACTIN served as control. B, C: Semiquantitative and quantitative RT-PCR of indicated

Reduction of NANOG expression by treatment of GCT-derived cells with chemical agents has been demonstrated before. The HDACi Apicidin and ATRA led to a prominent down-regulation of NANOG when applied to the EC cell line NCGIT (You et al., 2009). The Apicidin-induced down-regulation of NANOG led to loss of OCT3/4 and SOX2 expression as well as cell cycle arrest, inhibition of colony formation in soft agar and induction of differentiation into all three germ layers (You, et al., 2009). There, the authors discussed that targeting $N A N O G$ might be an approach for therapy of poorly differentiated GCTs. In light of our data from TCam-2 cells these recommendations cannot be extended to seminomas. Here treatment would represent no benefit for the patients.

We found that TCam-2 cells are sensitive to Depsi; they underwent apoptosis when treated markers $48 \mathrm{hr}$ after transfection of Nsi, NTsi, Tsi, and scrambled RNA (scr). $\Delta \Delta$ Ct-values of siRNA-transfected samples versus scrambled-siRNA-transfected controls are shown. GAPDH or HPRT (qRT-PCR) served as controls. [Color figure can be viewed in the online issue, which is available at wileyonlinelibrary.com.] with concentrations $\geq 10 \mathrm{~nm}$. In vitro, Depsi showed potent cytotoxic activities against human lung adenocarcinoma A549 and PC-9, human lung squamous cell carcinoma PC-1 and PC-10, human small cell lung carcinoma $\mathrm{ADH}$ and LX-1, human stomach adenocarcinoma MKN28 and MKN74, human mammary adenocarcinoma MCF-7 and ZR-75-1, and human colon adenocarcinoma Colo201 and SW480 ( $\mathrm{IC}_{50}: 555 \mathrm{pM}-5.92$ nM). In contrast, Depsi had weak cytotoxic activities against regular human endothelial cells HE9 and the activity was completely absent against human fibroblast cells $\left(\mathrm{IC}_{50}\right.$ : $\left.11.1 \mathrm{nM}-1.85 \mu \mathrm{M}\right)$ (Ueda et al., 1994). Additionally, Depsipeptide is selectively cytotoxic toward B-cell chronic lymphocytic leukemia cells $\left(\mathrm{LC}_{50}\right.$ : $\left.15 \mathrm{~nm}\right)$ as compared with normal mononuclear blood cells $\left(\mathrm{LG}_{50}\right.$ : 318 nм) (Byrd et al., 1999). Thus, the cytotoxicity on TCam-2 cells indicates that Depsi might represent 
A

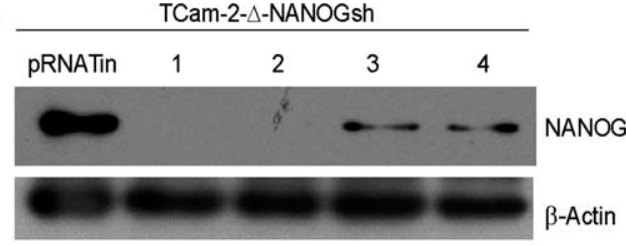

B

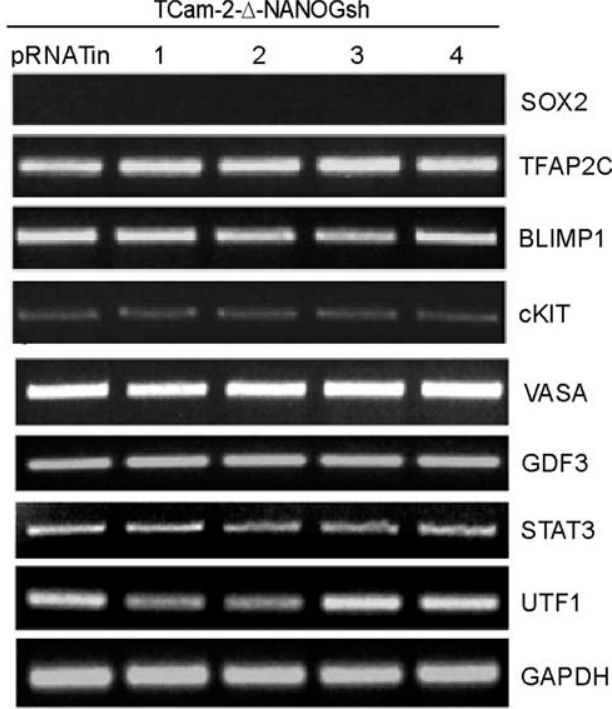

c

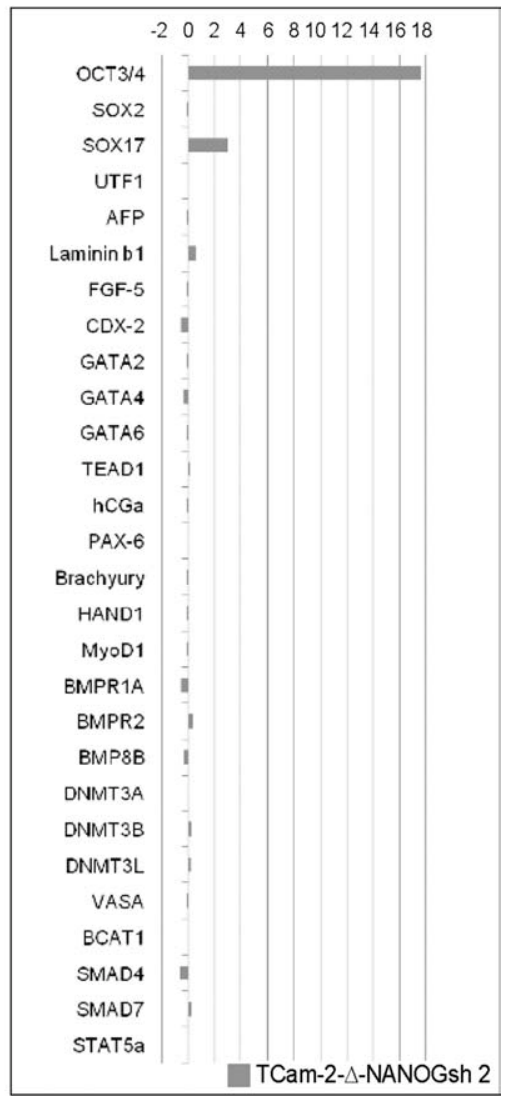

Figure 4. A: Western blot analysis of NANOG expression in TCam-2-ANANOGshl-4 and TCam2 cells expressing empty shRNA expression vector (pRNATin). $\beta$-ACTIN served as control. B: RT-PCR of markers indicated in TCam-2-DNANOGshl-4 and empty shRNA

a therapeutic option of patients diagnosed with seminoma.

Treatment of TCam-2 cells with Tranyl resulted in loss of methylation marks on lysines 4, 9, and 36 of histone 3. Interestingly, Tranyl treatment of breast cancer and neuroblastoma cell lines lead to the opposite effect, i.e., the increase of H3K4 methylation (Schulte et al., 2009; Lim et al., 2010). The lysine specific demethylase LSD1, which is expressed in TCam-2 cells, is a target of Tranyl, but Tranyl inhibits all MAOs and is not a specific LSD1 inhibitor. So the effects observed in TCam-2 cells might be due to interference with other MAOs. Therefore, TCam-2 cells might be a source to search for new molecular targets of Tranyl.

In human embryonic stem (ES) cells and EC cells, knock-down of NANOG leads to upregulation of the extraembryonic endodermassociated genes GATA4, GATA6, LAMININ-B1, and AFP (Mitsui et al., 2003) and to up-regulation of early trophectoderm-associated genes expression vector (pRNAT). GAPDH served as control. C: qRT-PCR of markers indicated in TCam-2- $\triangle$ NANOGsh2. $\Delta \Delta \mathrm{Ct}$-values of TCam-2- $\triangle$ NANOGsh2 versus untreated TCam-2 cells are shown. HPRT served as housekeeper control.

GATA2, CDX2, and HCG (Hyslop et al., 2005). We could show that the transient knock-down of NANOG in TCam-2 cells resulted in up-regulation of GATA2, GATA4 and weakly GATA6, but had no effect on LAMININ-B1, AFP, CDX2, and $H C G$. The up-regulation of DNMT3a and DNMT31 after transient reduction of NANOG expression could not be observed in the TCam-2$\triangle$ NANOGsh clones, indicating that TCam-2 cells are able to compensate for the loss of NANOG and maintain expression of the DNMTs. How do the TCam-2 cells achieve this? Expression levels of BLIMP1 and PRMT5 were not affected by NANOG knock down, indicating that the BLIMP1/PRMT5 mechanism, suppressing differentiation by maintaining a symmetric dimethylation of arginine 3 on histones $\mathrm{H} 2 \mathrm{a}$ and $\mathrm{H} 4$ (Ancelin et al., 2006) remains active. In addition, we observed up-regulation of OCT3/4 and SOX17 after knock down of NANOG. We hypothesize that the combination of the differentiation-inhibiting pathway orchestrated by BLIMP1/PRMT5 and 
the up-regulation of the pluripotency genes OCT3/4 and SOX17 might compensate for the loss of $N A N O G$.

The presented results further our understanding of germ cell as well as GCT biology and pinpoint Depsi as a possible therapeutic drug for the use in seminoma patients, while targeting $N A N O G$ in these GC'T entities is not of benefit for the patient.

\section{ACKNOWLEDGMENTS}

The authors thank Prof. Dr. A. von Rücker for providing Depsipeptide, Dr. S.Y. Lim for providing Tranylcipromine as well as antibodies. Furthermore, they thank Prof. H.-M. Jaeck for providing the BLIMP1 antibody and Robert Hardt for technical assistance.

\section{REFERENCES}

Ancelin K, Lange UC, Hajkova P, Schneider R, Bannister AJ, Kouzarides T, Surani MA. 2006. Blimp1 associates with Prmt5 and directs histone arginine methylation in mouse germ cells. Nat Cell Biol 8:623-630.

Battifora H, Sheibani K, Tubbs RR, Kopinski MI, Sun TT. 1984. Antikeratin antibodies in tumor diagnosis. Distinction between seminoma and embryonal carcinoma. Cancer 54:843-848.

Byrd JC, Shinn C, Ravi R, Willis CR, Waselenko JK, Flinn IW, Dawson NA, Grever MR. 1999. Depsipeptide (FR901228): A novel therapeutic agent with selective, in vitro activity against human Bcell chronic lymphocytic leukemia cells. Blood 94:1401-1408.

Chai G, Li L, Zhou W, Wu L, Zhao Y, Wang D, Lu S, Yu Y, Wang $\mathrm{H}$, McNutt MA, Hu YG, Chen Y, Yang Y, Wu X, Otterson GA, Zhu WG. 2008. HDAC inhibitors act with 5-aza-2'deoxycytidine to inhibit cell proliferation by suppressing removal of incorporated abases in lung cancer cells. PLoS One 3:e2445.

Chambers I, Colby D, Robertson M, Nichols J, Lee S, Tweedie S, Smith A. 2003. Functional expression cloning of Nanog, a pluripotency sustaining factor in embryonic stem cells. Cell 113:643-655

Czaja JT, Ulbright TM. 1992. Evidence for the transformation of seminoma to yolk sac tumor, with histogenetic considerations. Am J Clin Pathol 97:468-477.

Damjanov I, Horvat B, Gibas Z. 1993. Retinoic acid-induced differentiation of the developmentally pluripotent human germ cell tumor-derived cell line, NCCIT. Lab Invest 68:220-232.

de Jong J, Stoop H, Gillis AJ, Hersmus R, van Gurp RJ, van de Geijn GJ, van Drunen E, Beverloo HB, Schneider DT, Sherlock JK, Baeten J, Kitazawa S, van Zoelen EJ, van Roozendaal K, Oosterhuis JW, Looijenga LH. 2008a. Further characterization of the first seminoma cell line TCam-2. Genes Chromosomes Cancer 47:185-196.

de Jong J, Stoop H, Gillis AJ, van Gurp RJ, van de Geijn GJ, Boer M, Hersmus R, Saunders PT, Anderson RA, Oosterhuis JW, Looijenga LH. 2008b. Differential expression of SOX17 and SOX2 in germ cells and stem cells has biological and clinical implications. J Pathol 215:21-30.

Deb-Rinker P, Ly D, Jezierski A, Sikorska M, Walker PR. 2005. Sequential DNA methylation of the Nanog and Oct-4 upstream regions in human NT2 cells during neuronal differentiation. J Biol Chem 280:6257-6260.

Eckert D, Nettersheim D, Heukamp LC, Kitazawa S, Biermann K, Schorle H. 2008. TCam-2 but not JKT-1 cells resemble seminoma in cell culture. Cell Tissue Res 331:529-538.
Fabiani E, Leone G, Giachelia M, D'Alo F, Greco M, Criscuolo M, Guidi F, Rutella S, Hohaus S, Voso MT. 2010. Analysis of genome-wide methylation and gene expression induced by 5 -aza$2^{\prime}$-deoxycytidine identifies BCL2L10 as a frequent methylation target in acute myeloid leukemia. Leuk Lymphoma 51:2275-2284.

Ghoshal K, Datta J, Majumder S, Bai S, Kutay H, Motiwala T, Jacob ST. 2005. 5-Aza-deoxycytidine induces selective degradation of DNA methyltransferase 1 by a proteasomal pathway that requires the KEN box, bromo-adjacent homology domain, and nuclear localization signal. Mol Cell Biol 25:4727-4741.

Guan K, Chang H, Rolletschek A, Wobus AM. 2001. Embryonic stem cell-derived neurogenesis. Retinoic acid induction and lineage selection of neuronal cells. Cell Tissue Res 305:171-176.

Hyslop L, Stojkovic M, Armstrong L, Walter T, Stojkovic P, Przyborski S, Herbert M, Murdoch A, Strachan T, Lako M. 2005. Downregulation of NANOG induces differentiation of human embryonic stem cells to extraembryonic lineages. Stem Cells 23:1035-1043.

Lim S, Janzer A, Becker A, Zimmer A, Schule R, Buettner R, Kirfel J. 2010. Lysine-specific demethylase 1 (LSD1) is highly expressed in ER-negative breast cancers and a biomarker predicting aggressive biology. Carcinogenesis 31:512-520.

Mitsui K, Tokuzawa Y, Itoh H, Segawa K, Murakami M, Takahashi K, Maruyama M, Maeda M, Yamanaka S. 2003. The homeoprotein Nanog is required for maintenance of pluripotency in mouse epiblast and ES cells. Cell 113:631-642.

Mongan NP, Gudas LJ. 2007. Diverse actions of retinoid receptors in cancer prevention and treatment. Differentiation 75:853-870.

Monneret C. 2005. Histone deacetylase inhibitors. Eur J Med Chem 40:1-13

Oosterhuis JW, Looijenga LH. 2005. Testicular germ-cell tumours in a broader perspective. Nat Rev Cancer 5:210-222.

Pan G, Thomson JA. 2007. Nanog and transcriptional networks in embryonic stem cell pluripotency. Cell Res 17:42-49.

Salem CE, Markl ID, Bender CM, Gonzales FA, Jones PA, Liang G. 2000. PAX6 methylation and ectopic expression in human tumor cells. Int J Cancer 87:179-185.

Schulte JH, Lim S, Schramm A, Friedrichs N, Koster J, Versteeg R, Ora I, Pajtler K, Klein-Hitpass L, Kuhfittig-Kulle S, Metzger E, Schule R, Eggert A, Buettner R, Kirfel J. 2009. Lysine-specific demethylase 1 is strongly expressed in poorly differentiated neuroblastoma: Implications for therapy. Cancer Res 69:2065-2071.

Srigley JR, Mackay B, Toth P, Ayala A. 1988. The ultrastructure and histogenesis of male germ neoplasia with emphasis on seminoma with early carcinomatous features. Ultrastruct Pathol $12: 67-86$.

Strickland S, Mahdavi V. 1978. The induction of differentiation in teratocarcinoma stem cells by retinoic acid. Cell 15:393-403.

Thiagalingam S, Cheng KH, Lee HJ, Mineva N, Thiagalingam A, Ponte JF. 2003. Histone deacetylases: Unique players in shaping the epigenetic histone code. Ann N Y Acad Sci 983:84-100.

Ueda H, Manda T, Matsumoto S, Mukumoto S, Nishigaki F, Kawamura I, Shimomura K. 1994. FR901228, a novel antitumor bicyclic depsipeptide produced by Chromobacterium violaceum No. 968. III. Antitumor activities on experimental tumors in mice. J Antibiot (Tokyo) 47:315-323.

Weber S, Eckert D, Nettersheim D, Gillis AJ, Schafer S, Kuckenberg P, Ehlermann J, Werling U, Biermann K, Looijenga LH, Schorle H. 2010. Critical function of AP-2 gamma/TCFAP2C in mouse embryonic germ cell maintenance. Biol Reprod 82:214-223.

Wobus AM, Kaomei G, Shan J, Wellner MC, Rohwedel J, Ji G, Fleischmann B, Katus HA, Hescheler J, Franz WM. 1997. Retinoic acid accelerates embryonic stem cell-derived cardiac differentiation and enhances development of ventricular cardiomyocytes. J Mol Cell Cardiol 29:1525-1539.

You JS, Kang JK, Seo DW, Park JH, Park JW, Lee JC, Jeon YJ, Cho EJ, Han JW. 2009. Depletion of embryonic stem cell signature by histone deacetylase inhibitor in NCCIT cells: Involvement of Nanog suppression. Cancer Res 69:5716-5725.

Zhang B, Huang T, Liu K, Chen J, Wang G. 2007. Effects of 5Aza-CdR on cell proliferation of breast cancer cell line MDAMB-435S and expression of maspin gene. J Huazhong Univ Sci Technol Med Sci 27:543-546. 